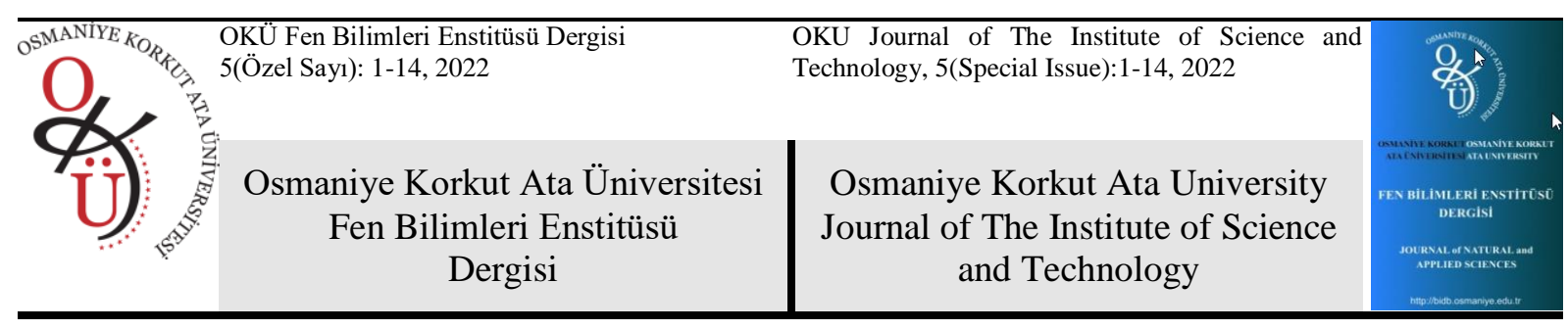

\title{
Fatigue Analysis of Welded Tubular Steel T-Joints
}

\author{
Gokhan YUCEL $^{1 *}$, Tugrul TALASLIOGLU ${ }^{2}$ \\ ${ }^{1,2}$ Osmaniye Korkut Ata University, Faculty of Engineering, Department of Civil Engineering, 80010, Osmaniye \\ ${ }^{1}$ https://orcid.org/0000-0002-2675-4607 \\ https://orcid.org/0000-0002-8075-4130 \\ *Corresponding author: gokhan.yucel@ osmaniye.edu.tr
}

\section{Research Article}

\section{Article History:}

Received: 08.12.2021

Accepted: 13.01.2022

Published online:23.02.2022

\section{Keywords:}

Fatigue

Wind turbine

Lattice structure

T-joint

Finite element modeling

\begin{abstract}
Fatigue damage occurs in steel joints exposed to repeated loads during their service life. Even if the design of lattice tubular structures that make up the steel skeletal structures is carried out according to certain regulations, the evaluations for determining the most critical fatigue damage in these structures are limited. Moreover, the discrete geometric configurations of trusses make it difficult to accurately predict fatigue damage. In this study, fatigue analyzes were performed on the planar T-joint sample with two different methods and under different boundary and loading conditions. Three-dimensional finite element models and three-dimensional welded joint detail were created to perform more accurate analysis. As a result, it has been determined that the fixed type support increases the fatigue life due to the increase in rigidity.
\end{abstract}

\section{T-Birleşimli Borusal Kaynaklı Çelik Yapının Yorulma Analizi}

\section{Araştırma Makalesi}

Makale Tarihçesi:

Geliş tarihi: 08.12.2021

Kabul tarihi:13.01.2022

Online Yayınlanma: 23.02.2022

\section{Anahtar Kelimeler:}

Yorulma

Rüzgar türbini

Kafes yap1

T-birleşim

Sonlu elemanlar modellemesi

\section{ÖZET}

Servis ömürleri içerisinde tekrarlı yüklere maruz kalan çelik birleşimlerde yorulma hasarları meydana gelmektedir. Çelik iskeletli yapıları oluşturan kafes boru şeklinde yapıların tasarımı belirli yönetmeliklere göre gerçekleştirilse de bu yapılardaki en kritik yorulma hasarının belirlenmesine yönelik değerlendirmeler kısıtlıdır. Dahası, kafes yapıların ayrık geometrik konfigürasyonları yorulma hasarının doğru bir şekilde tahmin edilmesini zorlaştırmaktadır. Bu çalışmada düzlemsel T-birleşim örneği üzerinde iki farklı yöntemle ve farklı sınır ve yükleme koşullarında yorulma analizleri gerçekleştirilmiştir. Üç boyutlu sonlu elemanlar modelleri ve üç boyutlu kaynaklı birleşim detayı daha gerçekçi analizler gerçekleştirmek için oluşturulmuştur. Sonuç olarak sabit tipli mesnetlemenin rijitlik artışı sebebiyle yorulma ömrünü artırdığı tespit edilmiştir.

To Cite: Yücel G., Talaslıglu T. Fatigue Analysis of Welded Tubular Steel T-Joints. Osmaniye Korkut Ata Üniversitesi Fen Bilimleri Enstitüsü Dergisi 2022; 5(Özel sayı): 1-14.

\section{Introduction}

The tubular lattice structures, which of joints are connected using a welding process are widely utilized to support the wind turbines due to having the more basic configuration, lower construction cost and easily renewable ability. Although their structural resisting capacity is determined in accordance with the appropriate design limitations, the assessment of their fatigue capacity is 
generally limited. Fatigue is an accumulative damage formation at any joints of the tubular lattice construction, which is caused by the repetitive loading application. Thus, the progression of fatigue is resulted with a localized damage without giving any warning at the beginning of repetitive loads. This complicated mode of failure has not been completely solved due to being managed by the fatigue mechanism depending on a crack dependent formation. Although the crack theory is solely well understood, the plasticity, which occurs during the propagation of crack, prevents establishing the fundamentals of a unique fatigue mechanism.

The fatigue phenomenon was firstly concerned by German Engineer August Möhler in the 18th century in a way of examining the failure reasons of steel profiles utilized in the railroad network. Although there does not exist a certain study to lay down the theoretical basis of fatigue damage in the 19th century, the first attempt in associating the fatigue formation with the crack issue became in the 20th century (Mann, 1970). The extensive review of fatigue failure is found in references (Cui, 2002; Fuštar et al., 2018; Wei et al., 2018; Feng et al., 2021; Gao and Liu, 2021; Hosseini et al., 2021).

The crack growth in the seam-welded structures is unfortunately influenced by some environmental factors, for example, the boundary and loading conditions, the surface quality, discontinuities in the weld geometry and weld geometric shapes, etc. This variety in the environmental factors causes to use the different fatigue assessment approaches in order to predict more accurately the fatigue lifetime of the welded structural system. Therefore, the different fatigue lifetime determination methods have been taken their places in the national or international design codes, for example, International Institution of Welding (IIW) (Hobbacher, 2019), Japanese (Japanese Society of Steel Construction (JSSC) 2012), British (BSI 1993) and Eurocode 3 (UNI EN 2005), etc.

In general, the stress and strain responses of structural elements are the main determinative factors for the prediction of fatigue lifetime. While the use of stress responses for the estimation of fatigue lifetime becomes to be more appropriate for low-cycle loading conditions, the high-cycle loading conditions require the use of the strain responses for a more accurate fatigue lifetime prediction. Particularly, the stress-based fatigue approaches are mostly utilized in the welded structural systems. The stress-based fatigue approaches are not only categorized depending on the use of stress type, for example, "nominal" (one of its types, "critical plane"), "structural stress" etc., but also the status of crack propagation (Lee et al., 2011). In fact, these categorizations of stress-based fatigue approaches are interacted. In general, whereas the structural stress-based fatigue approaches (SSF) are utilized at the initial level of crack, the critical plane stress-based approaches (CPF) at the micro-crack growth give more accurate results for the fatigue lifetime. It is noted that the principles of linear elastic fracture mechanics are also utilized depending on the propagation status of crack (Pinto et al., 2015; Jia and Hanbin, 2019).

Although the nominal stress-based approaches have relatively simple and practical features due to being mesh-independent, these approaches are generally resulted with more diverged estimation of fatigue lifetime for complex structures due to requiring a further fatigue category. Particularly, 
BS7608 as the provisions of British code (BSI 1993) prefers to estimate the fatigue lifetime using the nominal stress-based fatigue approach. The structural stress-based approaches achieve to obtain acceptable accuracy results through a little Finite Element modeling effort. However, it requires to use an appropriate size and arrangement of finite element. Furthermore, the crack propagation is only tackled for the weld toe (Aygul, 2013).

In certain engineering fields, for example, automotive engineering, the metal mechanical components are successfully designed against fatigue failure. However, the estimation of fatigue damage of steel constructions in structural engineering is resulted with a relatively diverged fatigue lifetime at the end of high computing cost. Because, the entire structural system is modelled using the certain finite elements, for example, plate, shell, or solids. Furthermore, it has to take into account of being represented its structural system as a discrete structural system instead of a unique mechanical component.

Moreover, the uncertainties, which are arisen from the nature of its discrete structural system, the variety in both the loading and boundary conditions and its joint connection types prevent obtaining a certain fatigue lifetime prediction considering the damage evaluation.

The primary reasons behind the fatigue damage are associated with the pre-and post-design stages in the construction of steel skeletal systems. While the fatigue lifetime in the pre-design stage is estimated depending on only the local part of steel skeletal construction instead of its entire construction in a way of omitting the manufacturing-related shortcomings, the lacks in the sustainable observations of steel constructional system throughout its existence lifetime against the fatigue damage are mostly encountered in the post-design stage. Particularly, it is noted that there also exist some attempts on the determination of loading conditions for the fatigue estimation of steel skeletal structures (Kajolli, 2013; Maheswaran, 2014).

Thus, this paper attempts to investigate the influence of using different loading and boundary conditions on the fatigue lifetime evaluation of typical T-joint in the steel skeletal structure. Particularly, it is also proposed to find out the critical welding regions of T-joint concerned with the fatigue failure under the different loading and boundary conditions. For this purpose, a sensitivity analysis of fatigue lifetime depending on the repetitive loading application is carried out.

\section{Finite Element Modeling and Structural Analysis of Tubular T-joint}

Generation of the Finite element mesh: Finite element analysis carried out using a well-known software Abaqus, 2019. The geometry and mesh of the tubular joint model are shown in Figure 1. The finite elements, which represent the parent plate, are formed using Abaqus Element named C3D8. The finite element model consists of 33335 nodes and 16626 elements in total. Since the stress levels are being in elastic limit under loads that cause fatigue, only elastic material properties were assigned. Young's modulus and Poisson's ratio were assigned to be $210 \mathrm{GPa}$ and 0.3 , respectively. The finite 
element sets in the model for the fatigue analysis described in the next section and element numbers for two different sets are given in Figure 2.

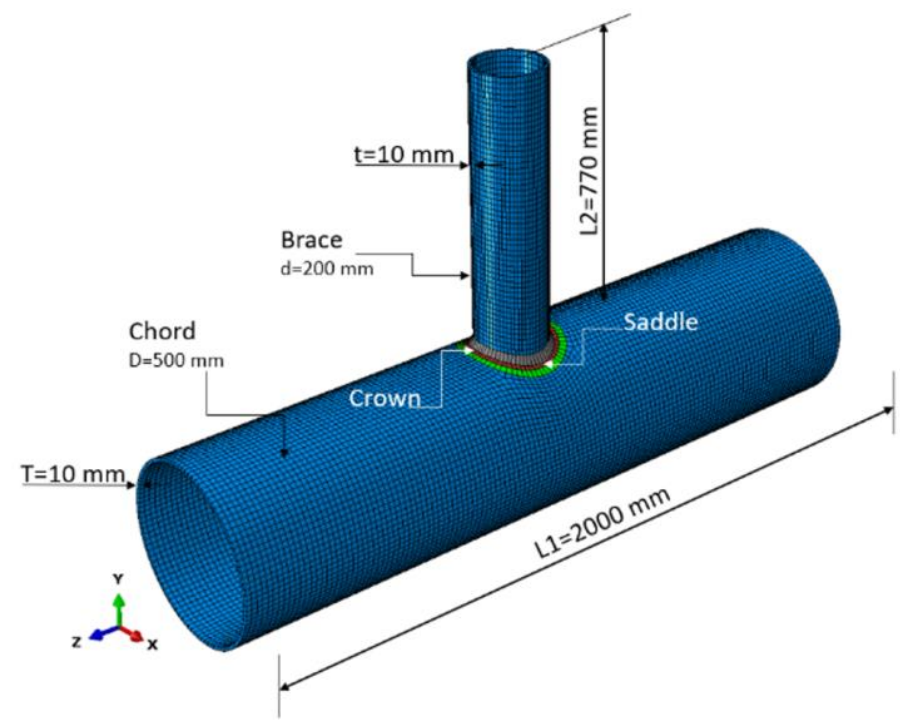

Figure 1. Geometry and finite element mesh of tubular T-joint

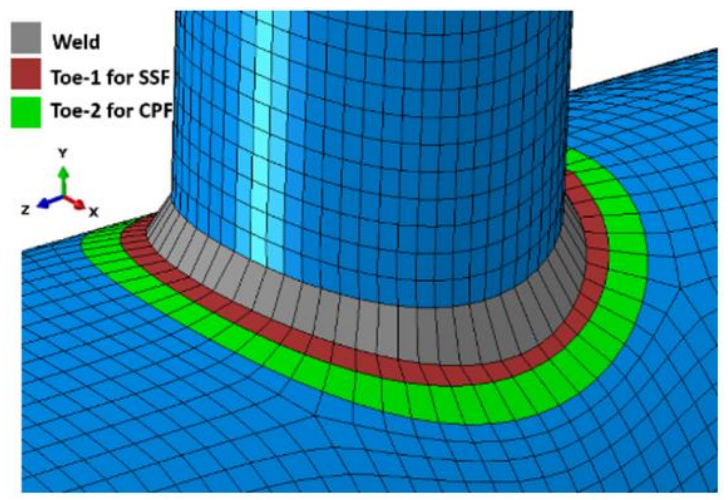

(a)

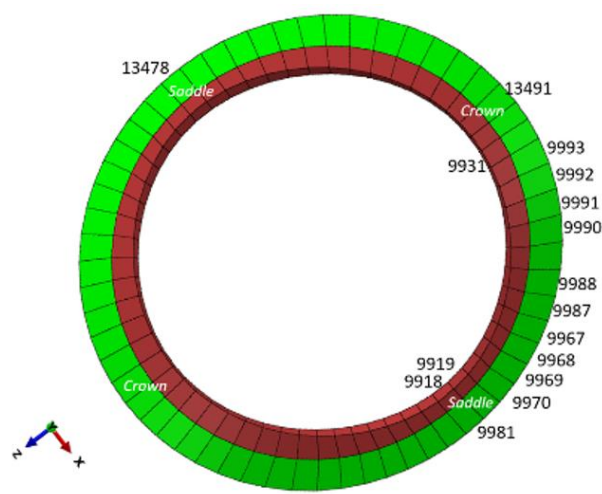

(b)

Figure 2. Element sets (a) and some of the element numbers for Toe-1 and Toe-2 sets (b)

Modeling of the weld profile: To obtain proper local stiffness and so the stress distribution, threedimensional weld geometry is also modeled (see Figure 2). Weld geometry was created considering the specifications given in the structural welding code ASW D1.1 (American Welding Society, 2015). With a reference to the brace and chord selected in $10 \mathrm{~mm}$ thickness, the finite element mesh size was determined as $10 \mathrm{~mm}$ and for the welding zone, C3D6 wedge elements are defined.

Establishment of Boundary and Loading Set Models: In this study, the influence of using different loading and boundary conditions on the fatigue lifetime evaluation of typical T-joint in the steel skeletal structure is examined. For this purpose, 6 different boundary types, which of connections are pinned and/or fixed are tackled for the simulation of T-joint (see Figure 3). Furthermore, 14 different loading scenarios, which of each represents a different loading combination are also purposed for each 
of these 6 different boundary conditions. In this regard, two different cases, which of each has a lower and higher magnitude are utilized to represent both axial and bending loadings. While each of the loading cases for the boundary types is presented in Table 1, the loading magnitudes and their combinations for these loading set models are tabulated in Tables 2 and 3. It is noted that the boundary types BT4, BT5, and BT6 seem to be more rigid with respect to ones, BT1, BT2, and BT3.

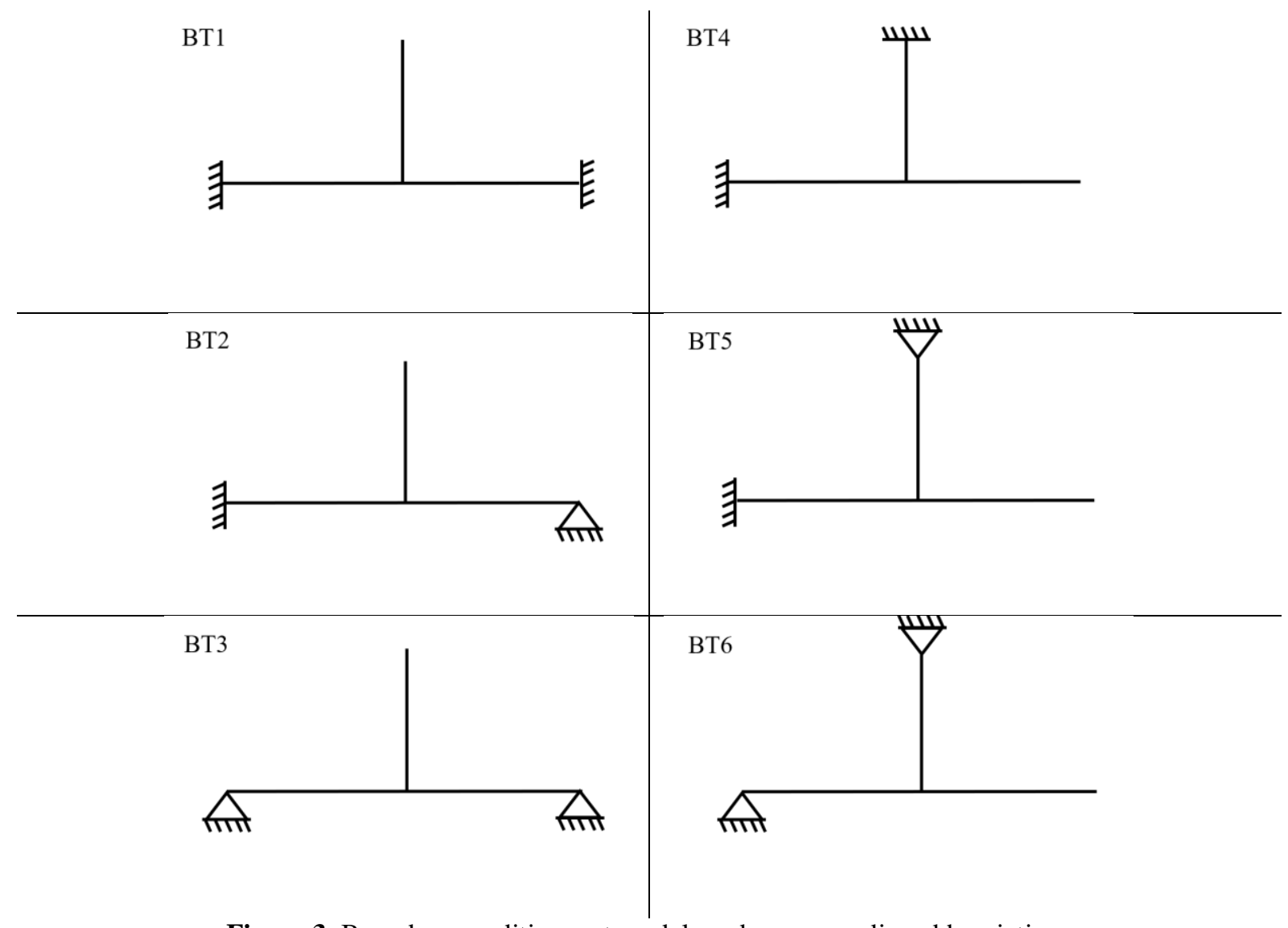

Figure 3. Boundary conditions set models and corresponding abbreviations

Structural Analysis Approach: As the nature of fatigue analysis, a linear type of structural analysis has to be computed the elastic structural response for the external static loads. In this study, the linear perturbation analysis as a structural analysis approach is employed to calculate the structural response corresponding to the base state of the finite element model, which is determined from the initial boundary and loading conditions. The main feature of linear perturbation analysis is its ability to be performed from time to time for the general response steps. This feature provides a big contribution for the computation of structural responses in case of any instability state of the purposed structural system. 
Table 1. Loading conditions for each of boundary condition set models

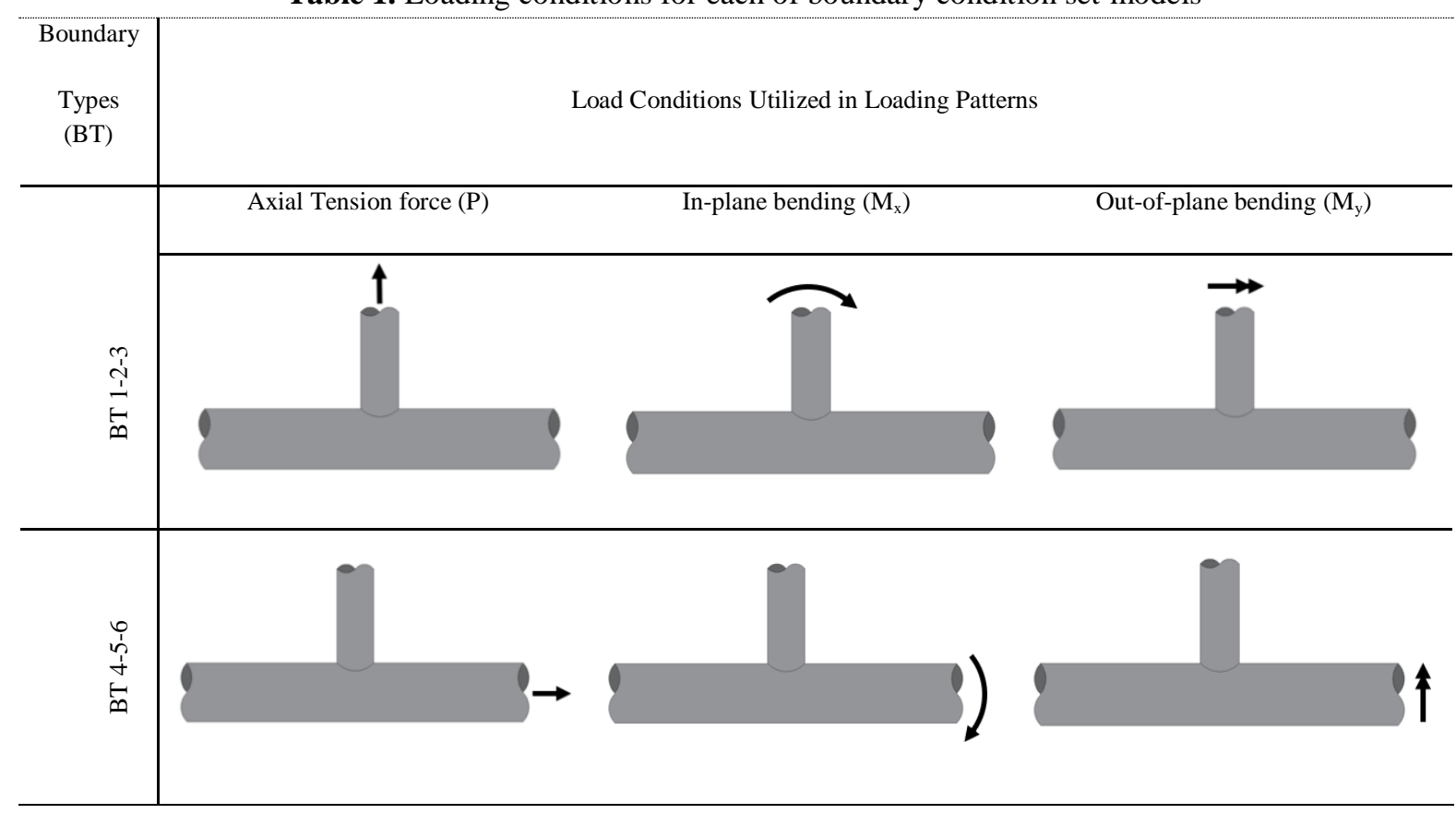

Table 2. Magnitudes of loadings for each of boundary condition set models

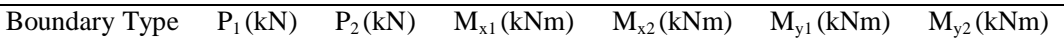

(BT)

\begin{tabular}{ccccccc}
\hline BT 1-2-3 & 10 & 100 & 1 & 5 & 1 & 5 \\
BT 4-5-6 & 200 & 1000 & 20 & 100 & 20 & 100 \\
\hline
\end{tabular}

Table 3. Combinations of loadings and corresponding abbreviations for each loading pattern

\begin{tabular}{|c|c|c|c|c|c|c|c|c|c|c|c|c|c|}
\hline LP1 & LP2 & LP3 & LP4 & LP5 & LP6 & LP7 & LP8 & LP9 & LP10 & LP11 & LP12 & LP13 & LP14 \\
\hline & & $\mathrm{P}_{1}$ & $\mathrm{P}_{1}$ & $\mathrm{P}_{2}$ & $\mathrm{P}_{2}$ & $\mathrm{P}_{1}$ & $\mathrm{P}_{1}$ & $\mathrm{P}_{1}$ & $\mathrm{P}_{1}$ & $\mathrm{P}_{2}$ & $\mathrm{P}_{2}$ & $\mathrm{P}_{2}$ & $\mathrm{P}_{2}$ \\
$\mathrm{P}_{1}$ & $\mathrm{P}_{2}$ & $\mathrm{M}_{\mathrm{x} 1}$ & $\mathrm{M}_{\mathrm{x} 2}$ & $\mathrm{M}_{\mathrm{x} 1}$ & $\mathrm{M}_{\mathrm{x} 2}$ & $\mathrm{M}_{\mathrm{x} 1}$ & $\mathrm{M}_{\mathrm{x} 1}$ & $\mathrm{M}_{\mathrm{x} 2}$ & $\mathrm{M}_{\mathrm{x} 2}$ & $\mathrm{M}_{\mathrm{x} 1}$ & $\mathrm{M}_{\mathrm{x} 1}$ & $\mathrm{M}_{\mathrm{x} 2}$ & $\mathrm{M}_{\mathrm{x} 2}$ \\
& & & & & & $\mathrm{M}_{\mathrm{y} 1}$ & $\mathrm{M}_{\mathrm{y} 2}$ & $\mathrm{M}_{\mathrm{y} 1}$ & $\mathrm{M}_{\mathrm{y} 2}$ & $\mathrm{M}_{\mathrm{y} 1}$ & $\mathrm{M}_{\mathrm{y} 2}$ \\
\hline
\end{tabular}

\section{Fatigue Assessment Approaches Utilized for Tubular T-joint}

The irregularities in the geometry along the weld line and the variation in the thickness of parent plates cause to be concentrated on the stresses in the certain location of the welded structural system. The use of the finite element method for the simulation of welded structural system, unfortunately, fails to obtain a consistent stress distribution due to being completely dependent on the meshing attribution. Nevertheless, to predict the fatigue lifetime more accurately for the welded structural system, the best reasonable approach is to regularize accordingly the stresses of finite element considering the notch and thickness effects.

In this regard, there are two possible approaches for the evaluation of multi-principal axial stresses: i) combining two in-plane principal stresses, named as "critical plane stress analysis" (BSI 1993), ii) 
summing the membrane and bending stresses taking into account of parent plate thickness, named as "equivalent structural stress analysis" (Dong, 2001; Dong and Hong, 2003). Although these two analysis approaches are valid for the larger loading cycles (e.g., 107) the weld geometry, and weld toe must be strictly modelled by use of equivalent structural stress-based fatigue approach rather than equivalent structural stress-based one. Particularly, the welding classification has to be defined for the critical plane stress-based fatigue approach neglecting the mean stress effect and the material properties of the parent plate.

\section{Formulations of fatigue assessment approaches:}

To estimate the fatigue lifetime, the S-N curve approach has a big attractive feature due to being easily correlated in accordance with the various joint types, loading conditions, etc. Particularly, the fatigue lifetime is easily computed using the critical plane stresses as

$$
N=\frac{K_{0}}{S^{m}}
$$

where $\mathrm{S}$ is the critical plane stress range, $\mathrm{N}$ is the fatigue lifetime, $\mathrm{K}_{0}$ is a constant for a particular weld classification, $\mathrm{m}$ is 3 to represent a constant curve slope on log-log axes in a range of fatigue lifetime $\left[10^{5}-10^{7}\right]$.

Although Eq. (1) is a very useful approach due to having a mesh-insensitive-computing procedure, requiring a new correlative regulation for every joint type, and loading condition makes it not to be a practical approach. Thus, the best way is to assign a different stress parameter. At this point, the equivalent structural stress begins to be utilized as an alternative to the critical plane stress. The working principles of the equivalent structural stress-based fatigue approach are managed depending on the parent metal thickness and the crack growth mechanism. Furthermore, the relative contribution of the membrane $\left(\sigma_{\mathrm{m}}=\mathrm{F}_{\mathrm{y}} /(1 * \mathrm{t})\right)$ and bending stresses $\left(\sigma_{\mathrm{b}}=6 * \mathrm{M}_{\mathrm{x}} /\left(1 * \mathrm{t}^{2}\right)\right)$ with respect to each other $\left(\sigma_{\mathrm{s}}=\sigma_{\mathrm{m}}+\sigma_{\mathrm{b}}\right)$ also play a big role for the estimation of fatigue lifetime depending on the welding length 1, vertical force Fy and bending moment $\mathrm{Mx}$ in the equivalent structural stress-based fatigue approach. Thus, the use of S-N curve $\left(\Delta \sigma_{\mathrm{s}}-\mathrm{N}\right)$ for the equivalent structural stress-based fatigue approach is governed by a two-stage growth model:

$$
\frac{d a}{d N}=C\left[f_{1}(\Delta K)_{a / t \leq 0.1} x f_{1}(\Delta K)_{a / t>0.1}\right]=C\left(M_{k n}\right)^{n}(\Delta K)^{m}
$$

where a stress intensity magnification factor $\mathrm{M}_{\mathrm{kn}}$ and stress intensity factor $\Delta K$ corresponding to first stage of crack growth $(0<\mathrm{a} / \mathrm{t}<0.1$ "small crack") and second stage of crack growth $(0.1<\mathrm{a} / \mathrm{t}<1$ "long crack"), a and $t$ are the magnitude of crack and the parent plate thickness. $n$ and $m$ are the constant growth exponent for the first stage of crack growth and the Paris Law exponent. Thus, after Eq. (3) is integrated, it is obtained: 


$$
N=\int_{a / t \rightarrow 0}^{a / t=1} \frac{d a}{C\left(M_{k n}\right)^{n}(\Delta K)^{m}}=\frac{1}{C}\left(t^{1-\frac{m}{2}}\right)\left(\Delta \sigma_{s}\right)^{-m}(I(r))
$$

where $\mathrm{I}(\mathrm{r})$ is a dimensionless function depending on a ratio of bending and membrane stresses $\left(\mathrm{r}=\Delta \sigma_{\mathrm{b}} /\left(\Delta \sigma_{\mathrm{b}}+\Delta \sigma_{\mathrm{m}}\right)\right), \Delta \sigma_{\mathrm{s}}$ is the structural stress range. It is noted that it is possible to write the structural stress range $\Delta \tau$ s for a shear dominated loading instead of the structural stress range $\Delta \sigma_{\mathrm{s}}$. The other governing parameter is related to the probability of failure depending on the number of standard deviations below the mean life. In this study, this criterion is determined as $50 \%$ for two fatigue assessment approaches. Moreover, the repetitive loading cases are assumed as a constant amplitude loading with a minimum load of zero, in other words $[1,0]$ or $\mathrm{R}=0$ presented in the context of Abaqus.

\section{Discussion}

\section{Effects of Loading and Boundary Conditions on Fatigue Damage and Lifetime}

The fatigue analysis is performed for each of these loading and boundary combinations, which are presented in Figure 3 and Tables (1-3), separately. Thus, considering the fatigue damage, it is possible to determine the most critical cases for the steel skeletal system, which supports the wind turbines.

In this framework, the fatigue lifetimes, which are the outcome from performing two different fatigue evaluation approaches for each of loading and boundary combinations are sketched in Figure 4. The infinite fatigue lifetime corresponding to no fatigue damage is visualized without any numerical value beyond $10^{10}$ in Figure 4. It is noted that the fatigue lifetime for each combination of loading and boundary conditions are evaluated using toe 1 and toe 2 for SSF and CPF, respectively (see Figure 2).

Considering of Table 4 and Figure 4, the preliminary remarks are drawn considering the combinations of loading and boundary conditions, for example, LP1\&BT1 and itemized as:

According to the location of fatigue damage

- The fatigue damage, which is obtained using the assessment of SSF does not occur for the lower loading conditions under almost all combinations of boundary conditions (see the term "ND" for LP1\&BT1, LP1\&BT2, LP1\&BT3 etc. in Table 4).

- The fatigue damage, which is obtained using the assessment of CPF occurs for all combinations of loading and boundary conditions.

- The critical element no's, which outcome from SSF and CPF assessments is consistently obtained as (9918, 9919 and 9931) and (9967, 9968, 9981, 13478 and 13491) for almost all combinations of loadings and BT1, BT2, and BT3 type boundary conditions (see Table 4). It is noted that the critical element no's, which outcome from CPF assessments becomes to be as 13478 and 13491 for the lower loading conditions and BT1, BT2 and BT3 type boundary conditions.

- Considering SSF assessment, it is mentioned that the lower loading conditions prevent the occurrence of fatigue damage (see the term "ND" for LP1\&BT4, LP3\&BT4, LP1\&BT5, and LP3\&BT5, etc. in Table 4). In the case of the higher loading conditions, the inclusion of out-of-plane 
bending moment into the current the loading conditions for the boundary conditions BT4 and BT5 does not cause the fatigue damage, which is obtained using SSF assessment, due to the existence of fixed-type boundary condition (see the term "ND" for LP7\&BT4, LP8\&BT4, LP7\&BT5 and LP8\&BT5 in Table 4). Another interesting result is also noted that the exclusion of fixed-type boundary condition prevents fatigue damage for the case of lower out-of-plane bending, in-plane bending moment and axial loading combination (see the term "ND" for LP7\&BT3 in Table 4).

- Considering SSF assessment, an increase in the rigidity plays a big role to be occurred the fatigue damage only in the critical element no 9931 for almost all types of loading and boundary conditions (see Table 4). Considering CPF assessment, an increase in the rigidity causes to be occurred the fatigue damage in the critical element no 9990, 9991, 9992, and 9993 for almost all types of loading and boundary conditions (see Table 4). However, in accordance with CPF assessment, the location of fatigue damage is completely removed from the element no 13478 for the boundary type BT4, BT5 and, BT6, which is utilized to represent the higher rigidity, due to the relatively an increase in either the in-plane bending moment or out-of-plane bending moment along with the in-plane bending moment.

- The most critical element no corresponding to the related fatigue analysis cases are also tabulated in Table 4. The stress contour plots with the deformed shapes at the end of structural analysis are presented for the most critical cases of loading and boundary conditions, LP4\&BT1 and LP4\&BT4 (see Figure 5a-5b). The fatigue log-lives at the end of fatigue analysis considering the fatigue assessment methods SSF and CPF are also presented for the most critical cases of loading and boundary conditions, LP4\&BT1 (see Figure 6a-6b). Some critical nodes are also presented for both toe 1 in brown color and toe 2 in green color in Figure 2.

\section{According to the fatigue lifetime}

- The fatigue lifetimes obtained using SSF assessment become to be higher than the other fatigue assessment approach, CPF (see Figure 4).

- As an expected situation, an increase in the severity degree in the loading conditions causes a decrease in the fatigue lifetime depending on the loading combinations. Particularly, an inclusion of out-of-plane bending into the loading combination makes a dramatic degradation in the fatigue lifetime (see the fatigue lifetimes in Figure 4).

- Considering the fatigue lifetimes, whereas the fixed-type boundary conditions increase the negative effect of the out-of-plane bending moment for the boundary conditions BT1 and BT2, the pinned-type boundary condition decreases this negative effect resulting in an increase in the fatigue lifetime (see the fatigue lifetimes for BT1 and BT2 along with BT3 in Figure 4). However, an increase in the rigidity makes the fixed-type boundary conditions to be more advantageous with respect to the pinned-type boundary condition and thus provides an elevation in the fatigue lifetime for the boundary 
conditions BT4 and BT5 even if being the negative effect of out-of-plane bending moment (see the fatigue lifetimes for BT4-BT6 in Figure 4).

Table 4. Critical element no obtained for each of boundary and loading conditions set models

\begin{tabular}{|c|c|c|c|c|c|c|c|c|c|c|c|c|}
\hline \multirow{3}{*}{$\begin{array}{c}\text { Loading } \\
\text { Patterns } \\
\text { (LP) }\end{array}$} & \multicolumn{12}{|c|}{ Boundary Types (BT) } \\
\hline & \multicolumn{2}{|c|}{ BT1 } & \multicolumn{2}{|c|}{ BT2 } & \multicolumn{2}{|c|}{ BT3 } & \multicolumn{2}{|c|}{ BT4 } & \multicolumn{2}{|c|}{ BT5 } & \multicolumn{2}{|c|}{ BT6 } \\
\hline & SSF & CPF & SSF & CPF & SSF & CPF & SSF & CPF & SSF & CPF & SSF & CPF \\
\hline LP1 & ND & 13491 & ND & 13491 & ND & 13491 & ND & 9991 & ND & 9990 & ND & 9990 \\
\hline LP2 & 9918 & 13491 & 9918 & 13491 & 9918 & 13491 & 9931 & 9991 & 9931 & 9990 & 9931 & 9990 \\
\hline LP3 & ND & 13491 & ND & 13491 & ND & 13491 & ND & 13491 & ND & 13491 & 9931 & 13491 \\
\hline LP4 & 9931 & 13478 & 9931 & 13478 & 9931 & 13478 & 9931 & 13491 & 9931 & 13491 & 9931 & 13491 \\
\hline LP5 & 9918 & 13491 & 9918 & 13491 & 9918 & 13491 & 9931 & 9992 & 9931 & 9992 & 9931 & 9992 \\
\hline LP6 & 9918 & 9967 & 9918 & 9967 & 9918 & 9967 & 9931 & 13491 & 9931 & 13491 & 9931 & 13491 \\
\hline LP7 & 9918 & 9968 & 9918 & 9968 & ND & 9968 & ND & 9991 & ND & 9991 & 9931 & 9991 \\
\hline LP8 & 9918 & 9981 & 9918 & 9981 & 9918 & 9981 & ND & 9987 & ND & 9970 & 9931 & 9969 \\
\hline LP9 & 9919 & 9967 & 9919 & 9967 & 9919 & 9967 & 9931 & 13491 & 9931 & 13491 & 9931 & 13491 \\
\hline LP10 & 9918 & 9968 & 9918 & 9968 & 9918 & 9968 & 9931 & 9991 & 9931 & 9991 & 9931 & 9993 \\
\hline LP11 & 9918 & 9968 & 9918 & 9968 & 9918 & 9968 & 9931 & 9991 & 9931 & 9991 & 9931 & 9991 \\
\hline LP12 & 9918 & 9968 & 9918 & 9968 & 9918 & 9968 & 9931 & 9988 & 9931 & 9988 & 9931 & 9991 \\
\hline LP13 & 9918 & 9967 & 9918 & 9967 & 9918 & 9967 & 9931 & 13491 & 9931 & 13491 & 9931 & 13491 \\
\hline LP14 & 9918 & 9968 & 9918 & 9968 & 9918 & 9968 & 9931 & 9991 & 9931 & 9991 & 9931 & 9991 \\
\hline
\end{tabular}

ND: No Damage, SSF: structural stress-based fatigue approach, CPF: critical plane stress-based approach
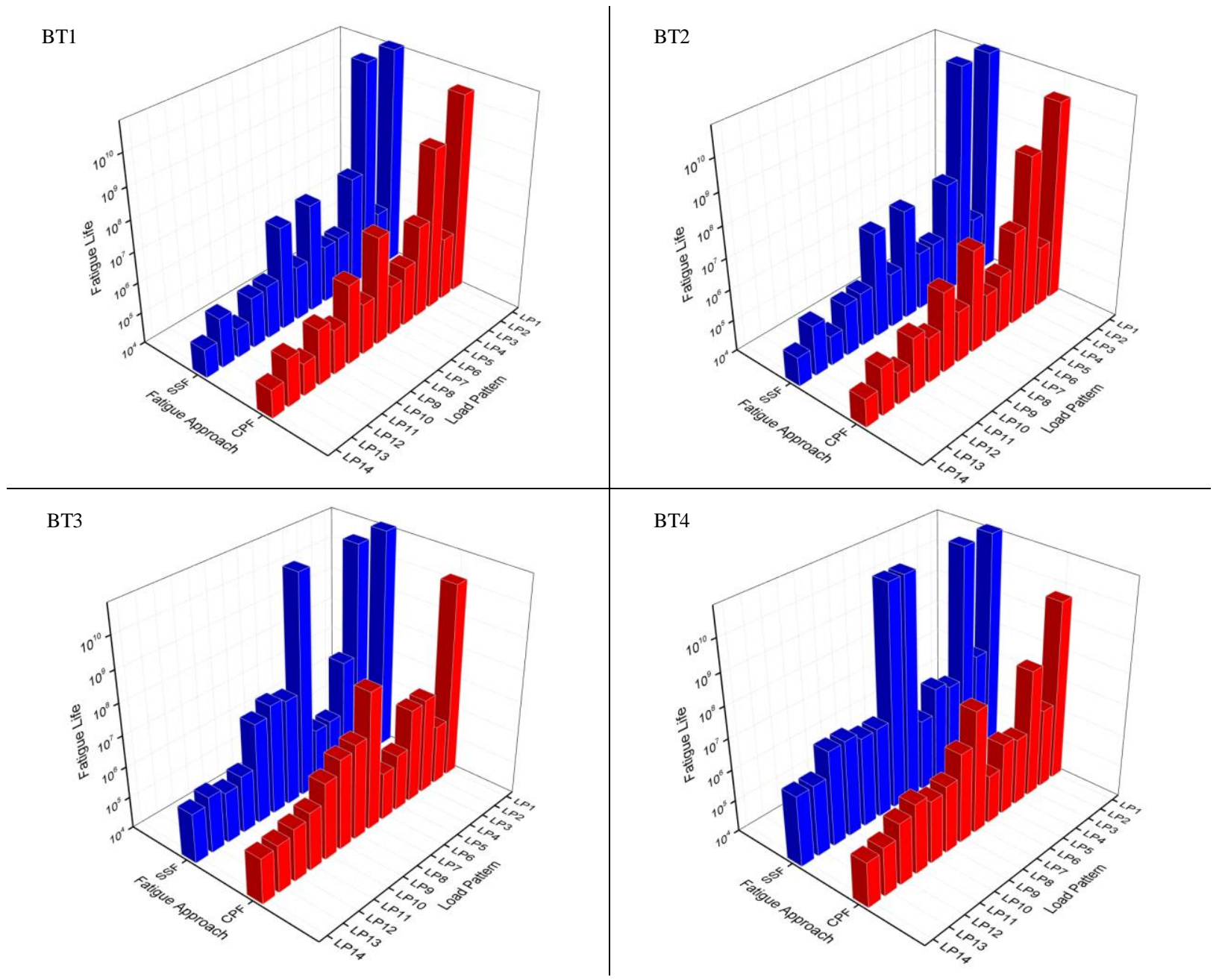

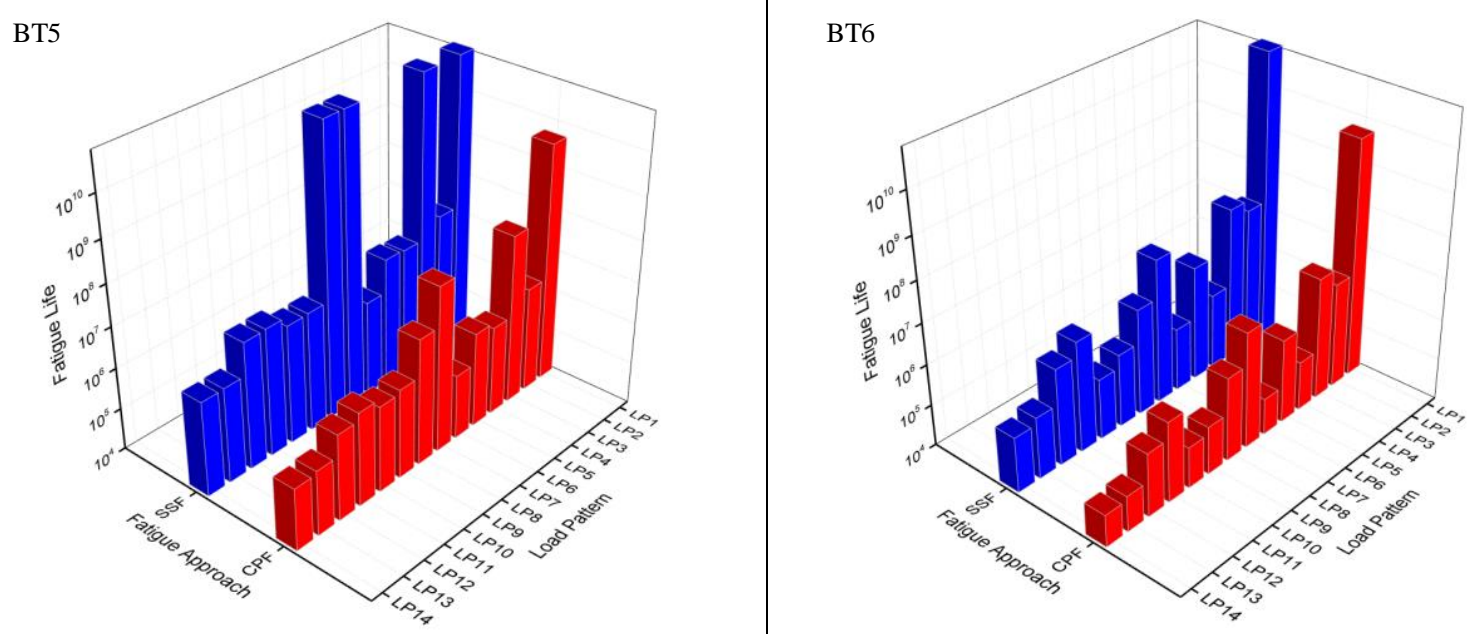

Figure 4. Fatigue lifetime for each boundary type (BT) obtained using the fatigue approaches

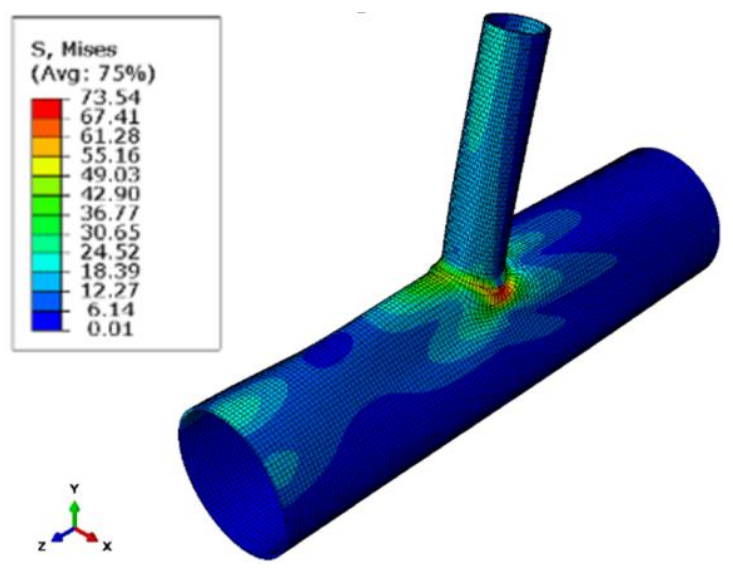

(a)

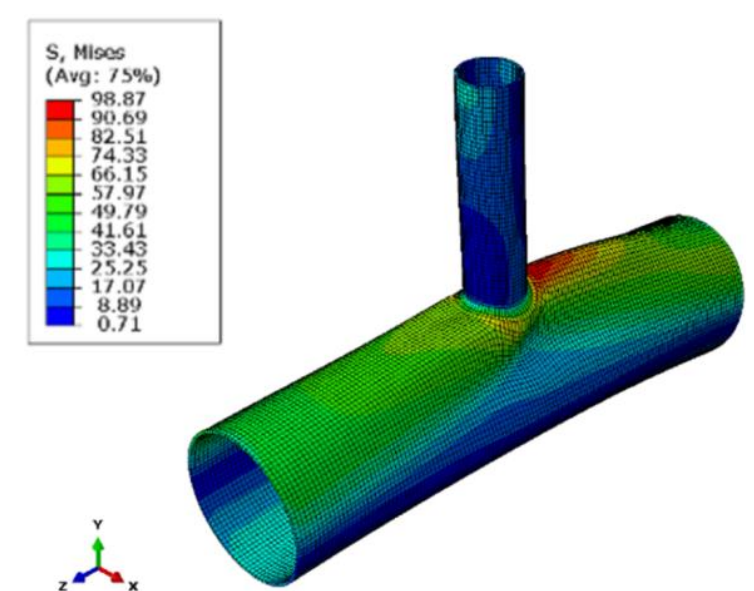

(b)

Figure 5. Stress distribution for model under LP4\&BT1 (a) and LP4\&BT4 (b)

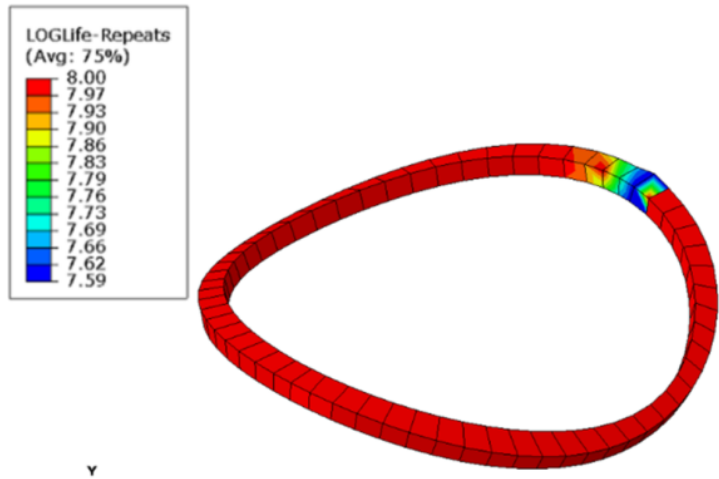

$\stackrel{2}{2}$

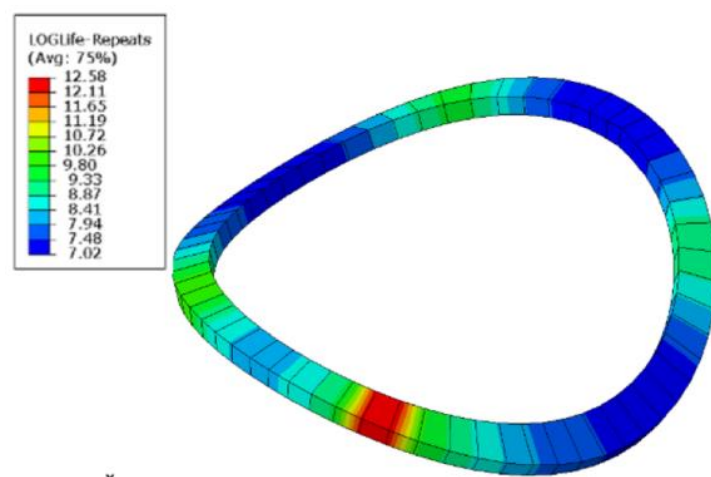

策

(a)

(b)

Figure 6. Fatigue lifetimes obtained using SSF (a) CPF (b) approaches for model under LP4\&BT1 


\section{Conclusion}

This study investigates the loading and boundary conditions on the fatigue lifetime depending on the fatigue damage for T-type joint connection of tubular lattice girder. In this regard, a total of 14 different loading combination sets are applied for 6 structural systems with different boundary condition combination sets. Then, the following important remarks are briefly summarized as:

- $\quad$ The assessment method named SSF for the lower loading and all boundary conditions cannot provide a consistent evaluation for the fatigue damage.

- The increase in the in-plane bending moment causes to be gathered the fatigue damage on the crown and saddle regions of T-connection considering the assessment methods of SSF and CPF. However, the increase in the rigidity causes to be occurred the fatigue damage on the crown region of T-connection considering the assessment methods of CPF.

- The fatigue lifetimes obtained using SSF assessment become to be higher than the fatigue assessment approach, CPF.

- $\quad$ An inclusion of out-of-plane bending moment into any loading cases causes correspondingly to decrease the fatigue lifetime of the structural system.

- The inclusion of the fixed-type boundary conditions rather than the pinned-type one into the structural system causes a negative contribution to the fatigue behavior of the structural system in a way of decreasing its fatigue lifetime. However, through an increase in the rigidity of the structural system, the inclusion of the fixed-type boundary conditions into the structural system provides to be an increase in its fatigue lifetime.

As a next work, the fatigue analysis will be extended including the adjoining regions beyond the end of the welding line in a way of altering the mesh size of the finite element model. Moreover, the discontinuities in the weld line and weld geometry will be investigated on the effect of fatigue lifetime.

\section{Declaration of Competing Interests}

The authors declare that they have no competing interests that could have influence the work reported in this paper.

\section{Credit Author Statement}

Gokhan Yucel: Visualization, Writing-Original draft preparation, Writing - Review \& Editing, Formal Analysis. Tugrul Talaslioglu: Conceptualization, Methodology, Supervision, Investigation, WritingOriginal draft preparation, Writing - Review \& Editing.

*This study was presented as a summary paper at the International Conference on Engineering, Natural and Applied Sciences (ICENAS'21) held online on 24-26 November 2021. 


\section{References}

Abaqus. Dassault Systemes Simulia Corp. Jonhston, RI, USA, 2019.

American Welding Society. AWS D1.1/D1.1M:2015 An American National Standard Structural Welding Code-Steel.

Aygul M. Fatigue evaluation of welded details- Using the finite element method. Doctoral dissertation, Chalmers University of Technology, 2013 Gothenburg, Sweden.

BSI. BS 7608:1993 Code of Practice for Fatigue Design and Assessment of Steel Structures." British Standards Institution, 1993.

Cui W. A state-of-the-art review on fatigue life prediction methods for metal structures. Journal of Marine Science and Technology 2002; 7(1): 43-56.

Dong P. A structural stress definition and numerical implementation for fatigue analysis of welded joints. International Journal of Fatigue 2001; 23(10): 865-876.

Dong P., Hong JK. Analysis of hot spot stress and alternative structural stress methods. in Proceedings of the International Conference on Offshore Mechanics and Arctic Engineering - OMAE 2003; pp. 213-24.

Feng R., Xu J., Chen Z., Roy K., Chen B., Lim JB. Numerical investigation and design rules for stress concentration factors of stainless-steel hybrid tubular joints. Thin-Walled Structures 2021; 163, 107783.

Fuštar B., Lukačević I., Dujmović D. Review of fatigue assessment methods for welded steel structures. Advances in Civil Engineering 2018.

Hobbacher AF. Erratum to: Recommendations for fatigue design of welded joints and components. Springer, Cham 2019.

Hosseini AS., Zavvar E., Ahmadi H. Stress concentration factors in FRP-strengthened steel tubular KT-joints. Applied Ocean Research 2021; 108, 102525.

Gao K., Liu G. Novel nonlinear time-varying fatigue reliability analysis based on the probability density evolution method. International Journal of Fatigue 2021; 149, 106257.

Japanese Society of Steel Construction (JSSC). Fatigue design recommendations for steel structures 2012.

Jia LJ., Hanbin G. Ultra-low-cycle fatigue failure of metal structures under strong earthquakes. Springer 2019; 177-196.

Kajolli R. A new approach for estimating fatigue life in offshore steel structures. Master's thesis, University of Stavanger, 2013 Norway.

Lee YL., Mark B., Hong TK. Metal fatigue analysis handbook. Elsevier, 2011.

Maheswaran J. Fatigue life estimation of tubular joints in offshore jacket according to the SCFs in DNV-RP-C203, with comparison of the SCFs in ABAQUS/CAE. Master's thesis, University of Stavanger, 2014, Norway.

Mann JY. Bibliography on the fatigue of materials. Components and Structures. 1st ed. 1970 
Pergamon.

Pinto H., Álvaro P., Ignacio A. Exponential model for damage accumulation in closed cell aluminum foams. Revista de La Construccion 2015; 14(2): 80-85.

UNI EN. BS EN 1993-1-9:2005- Eurocode 3: Design of Steel Structures-Part 1-9: Fatigue. in Eurocode 3, 2005.

Wei X., Zongyi W., Lin X., Chentai W. Review of fatigue assessment approaches for tubular joints in CFST trusses. International Journal of Fatigue 2018; 113, 43-53. 